\title{
SCENARIOS IN A RATIONAL APPROACH TOWARDS PLANNING UNDER UNCERTAINTY
}

\author{
Lozan BIZOV
}

\begin{abstract}
The implementation of the scenario approach at all levels in the modern national security process is unavoidable. As long as it is not part of the Bulgarian military practice yet, there is a need the idea to be communicated, and sound explanations provided in terms of rationalizing the defense and force planning process.
\end{abstract}

Keywords: Scenarios, scenario planning, planning scenarios, contextual scenario, situational scenario.

Let us assume that a scenario is a description of an event or a combination of actions and events, which represents a story about something that is going to happen in the future. ${ }^{1}$ Certainly, there are more complicated and advanced definitions, but as a very generic one this definition will serve the needs of the article.

\section{A Tool, Which Is Worth the Effort to Be Developed, Learned and Exploited}

Scenarios and scenario-based techniques are being used owing to their flexibility and rational treatment of the future, which of course is subjective, but because of this embedded rationalism scenarios strike a good balance between the objective and subjective. One possible and promising area for scenario implementation is in the field of planning - more precisely in the process of planning. The area that would benefit most is mid- and long-term planning related to national security issues. Some may ask - but why not short-term defense planning. The answer is obvious - due to the duration of these plans the uncertainty is lower and forecasting and other similar techniques are more suitable for such one- to three-year periods. However, when we are planning for periods of 4 to 8 years or 10 to 15 or more, uncertainty gets higher, the combinations of the driving factors/variables increase and as a result a set of futures or future worlds becomes a reasonable substitution of the single line of development approach. Applying the terminology adopted for the use of scenarios in the process of planning allows us to say that we exploit scenario-based planning. This type of plan- 


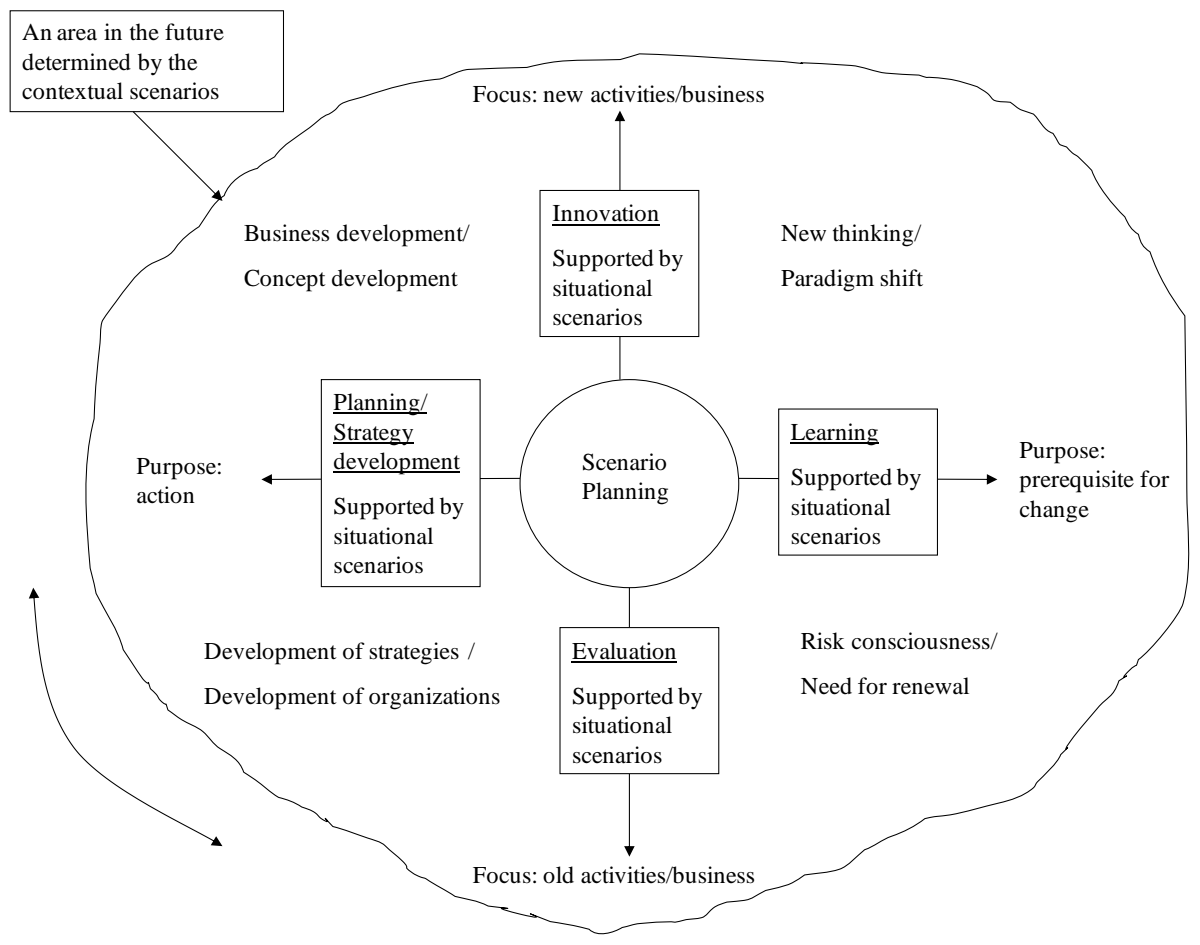

Figure 1: Summary of the Various Uses of Scenarios.

ning is assumed to be efficient when developing mid- and long-term plans in uncertain conditions. ${ }^{2}$

\section{Why Scenarios?}

In order to develop scenarios, different combinations of preliminary determined driving variables/ factors are used. This approach is so productive that in no time all the calculating and analytical power we posses will be overrun by swarms of scenarios. Here the "craftsmanship" of the scenario developers shows up. It is directed towards reducing these big amounts of scenarios into a useful and representative set of plausible futures - a chosen few out of hundreds of thousands. With this small set we can proceed further, but there is no need to neglect the benefits of scenario writing as a tool for learning. Thinking in the context of a scenario helps us to understand the logic that guides the development, clearly shows the driving forces, key factors, key players and our own potential to exert influence. ${ }^{3}$ Also, it is good to know and be able to make a distinction between scenario planning and a planning scenario. Scenario planning is a process, which produces scenarios. While, planning scenarios are the 
items we use in the planning process to derive conclusions in mid- or long-term planning and in the end of that process create a plan or a set of plans or another form of a decision.

In this article, the scenarios are divided into two categories: contextual and situational. In short, the contextual scenario represents "a single way to a future," while the situational one is "simply a description of a single future situation," which may occur in one or more contextual scenarios. The use of scenarios for different purposes is illustrated in Figure 1. ${ }^{6}$

As can be observed from the figure, the scenario-planning process is in the center of our universe. The representative set of contextual scenarios or future worlds forms the outer shape. Within this shape are locked all valuable situational scenarios, which we may use for learning, evaluation, planning or strategy development and for innovation. These are four possible processes, each of which we feed with situational scenarios occurring in a certain context aiming to achieve a purpose or to stay focused on an issue. The importance of the scenario techniques gets even more evident when we look at the existing combinations among the pair of axes. The focus here ranges from transformational paradigm shift to risk consciousness, organizational and business development. The value of the scenarios for long-term defense planning becomes obvious in terms of the practical approaches represented in Figure 1.

The benefits from the scenario approach to long-term defense planning will become even clearer when the applications shown in Figure 1 are analyzed in the context of the notional national security process as presented in Figure $2 .^{7}$

Figure 2, viewed in the context of Figure 1, shows that the need to apply the scenario approach at strategic level appears due to a guiding document called here Security Strategy at National Level. In the context of Bulgaria, the period covered by this strategy is approximately four years (notional), which is a short period, but from the other hand there is no meaning to build a strategy just for four years and the next political formation to develop an opposite one. The occurrence of this controversial situation is reduced through the constant set of security requirements, imposed over the political formation in power by the Constitution of the country. From this starting point, there will be no problem at strategic level when political formations change since the difference in the strategy they announce will originate from the currently existing or expected in the near future opportunities and threats in order to best satisfy the national interests related to national security. The role of the National Assembly as an institution able to balance any severe deviation imposed by a very biased Security Strategy at National Level cannot be neglected. So, as an ideal result, this will allow steady direction in terms of national security to be followed, which means that the use of scenarios will become more and more relevant. In addition, all 


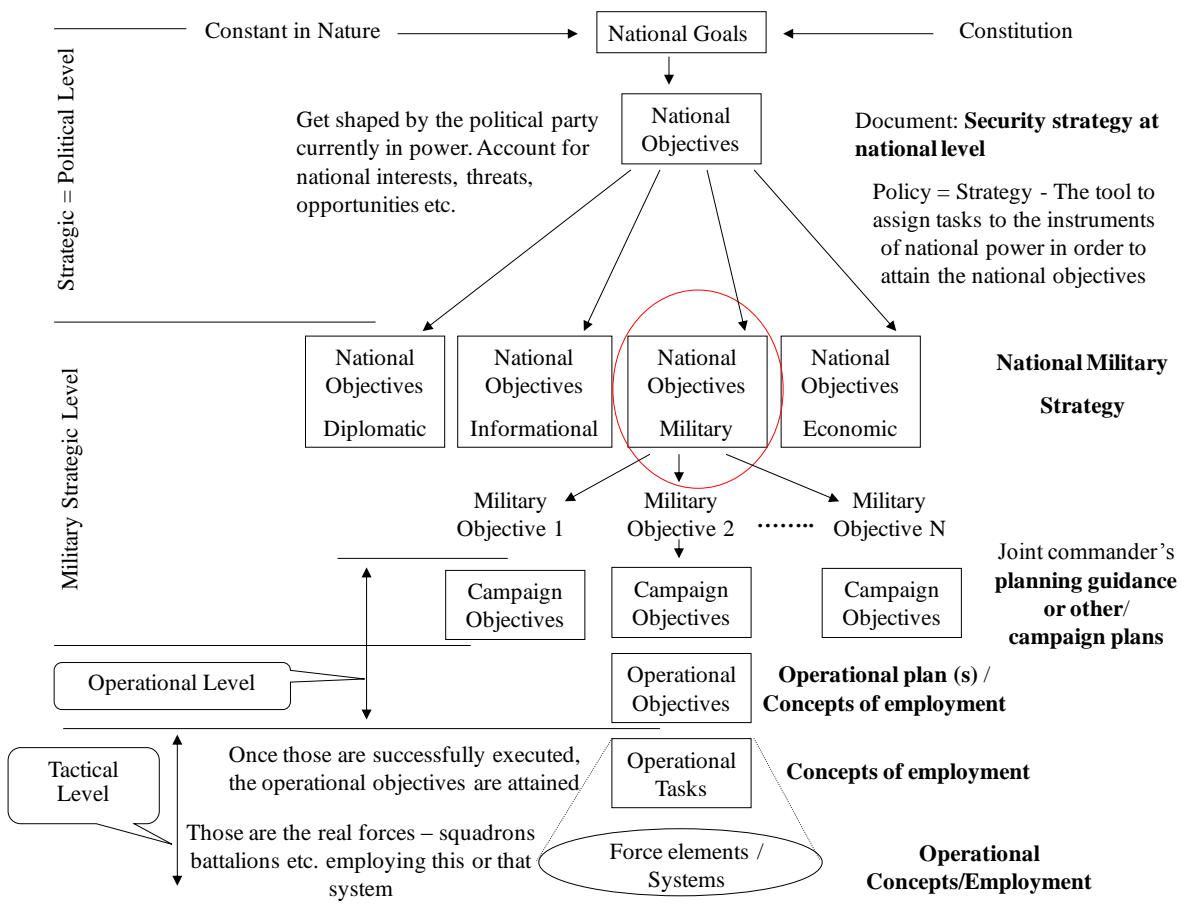

Figure 2: Top-Bottom Approach in the National Security Process.

ideas communicated in the strategy document are broad in nature but they set the stage for continuation of the national security process.

At Military Strategic level, the response to the objectives stated in the Security Strategy at National Level is called National Military Strategy. More or less this is the document where the main issues related to the country's armed forces have to be outlined. Depending on the current and expected in long-term security context, here are the main prospects of development and objectives - are the armed forces offensive or defensive, are they going to be deployable, what is the structure, the intention of their use, support and so on. All these are very general and high-level statements in support of the national security objectives and the scenario approach is the tool, which is going to justify these big and important for the country decisions. Here the following point has to be stated clearly. If a subjective analysis serving political biases is needed, it could be easily obtained; however, this may threaten the very existence of the country. The only way to safeguard the scenario approach from subjectivity is through a fair and open work. Decisions have to be made based on highly objective results, not manipulated through speculations with biased scenarios. Not needless to say, the analysis of the driving variables, the formation of the set of 
representative scenarios, the development of the contextual scenarios engaging the military instrument of national power, the development of the operational tasks and the required operational capabilities for the armed forces is a very difficult and hard process. It is reasonable at this level to expect an input from the higher level in terms of approved contextual scenarios, broad enough to allow creative thinking at the lower level in terms of adjusting those scenarios for the needs of the armed forces. With this idea in mind, we may say that the political leadership backed up by the military professionals will use the scenarios as a tool in defense planning, while at strategic military level the same tool, adjusted accordingly, will be used for force planning.

At the subsequent Campaign and Operational Levels, the use of scenarios is for contingency plans development, operational concepts development, testing of ideas, concepts or plans. All these activities within the military establishment are more or less interrelated and they require participation of personnel at/from the higher and lower levels. The approach applying the scenario techniques is mainly top-down (strategy to task), but a bottom-up approach is also required and beneficial especially in terms of testing new and promising technologies, systems and tactical units.

Finally, the scenario driven capability-based planning ${ }^{8}$ is the way to get ready today for the uncertain and rapidly changing tomorrow, where cost effective but at the same time capable instruments of national power will be required to participate in the defense of national, alliance and/or coalition objectives in support of the national security goals. 


\section{Notes:}

1 Wikipedia the free encyclopedia - Definition of a Scenario, <en.wikipedia.org/wiki/ Scenario> (17 December 2007).

2 Mats Lindgren and Hans Bandhold, Scenario Planning: The Link between Future and Strategy (Palgrave Macmillan, February 2003), 24.

${ }^{3}$ Lindgren and Bandhold, Scenario Planning: The Link between Future and Strategy, 25.

${ }^{4}$ NATO Research and Technology Organisation, Handbook on Long Term Defense Planning, RTO Technical Report RTO-TR-069 AC/323(SAS-025)TP/41 (St. Joseph Print Group Inc, April 2003), A1-1. This definition deals with developmental scenarios, but in the work on NATO SfP981149 project we found it more relevant to label these scenarios contextual scenarios.

5 NATO Research and Technology Organisation, Handbook on Long Term Defense Planning.

${ }^{6}$ Lindgren and Bandhold, Scenario Planning: The Link between Future and Strategy, 25, Figure 2.3. The author finds the figure relevant and builds over it according to the ideas expressed in this article.

7 This figure is a compilation of the ideas expressed in David E. Thaler, Strategies to Tasks: A Framework for Linking Means and Ends (Santa Monica, CA: RAND Corporation, 1993), p. 4, Figure 1, p. 5, 6, 7, and 8 and Dennis M. Drew and Donald M. Show, Making Strategy: An introduction to National Security Processes and Problems (Alabama: Maxwell Air Force Base, Eight Printing, Air University Press, September 2002), p. 23, Figure 1.

8 The term was used by Dr. Todor Tagarev during the research work conducted in the spring and summer of 2007 as part of the activities related to NATO SfP981149 project.

LOZAN BIZOV is Assistant Professor in the Air Force Department of the "G. S. Rakovski" Defense and Staff College in Sofia, Bulgaria. He holds Masters degrees in Electronics and Computation Systems from Bulgaria's Air Force Academy (1992) and in Operational Art and Science from the U.S. Air Command and Staff College, Maxwell AFB, Alabama (2003). Major Bizov has served at a variety of positions at Dobroslavtsi Air Base (1992-2000) and in the Interoperability Department of "G. S. Rakovski" Defense and Staff College (2000-2004), as well as in SFOR, Bosnia and Herzegovina (1997-1998). His professional interests include planning and execution of combined and joint air operations; air doctrine, and advanced air force-related technologies. E-mail: lozanmb@abv.bg. 